\author{
С. Ю. МАЛКОВ ${ }^{1}$, \\ О. И. ДАВЫДОВА ${ }^{2}$ \\ ${ }^{1}$ Институт экономики Российской академии наук, г. Москва, Россия \\ ${ }^{2}$ «Айдесайд Консалтинг», г. Королев, Россия

\section{МАТЕМАТИЧЕСКАЯ МОАЕАЬ АИЯ АНАЛИЗА ВЗАИМОСВЯЗИ АЕНЕЖНОГО ОБРАЩЕНИЯ И ЭКОНОМИЧЕСКОГО РОСТА В РАЗВИВАЮЩИХСЯ СТРАНАХ}

\author{
Контактное лицо: \\ Малков Сергей Юрьевич, доктор технических наук, профессор, Институт экономики \\ Российской академии наук \\ Адрес: 117218, г. Москва, Нахимовский просп., 32 \\ E-mail: s@malkov.org \\ ORCID: https://orcid.org/0000-0002-9654-1439 \\ Researcher ID: http://www.researcherid.com/rid/L-5734-2015 \\ Давыдова Ольга Игоревна, аналитик, ООО «Айдесайд Консалтинг» \\ Адрес: 141070, Московская обл., г. Королев, ул. Калинина, $6 б$ \\ E-mail: davydova.olga.msk@gmail.com \\ ORCID: http://orcid.org/0000-0001-5308-3143 \\ Researcher ID: http://www.researcherid.com/rid/Q-2740-2018
}

Цель: разработка базовой математической модели, позволяющей оценивать применительно к развивающимся странам влияние внешней торговли на национальную экономику, влияние курса национальной валюты на экономический рост. Методы: при разработке модели используются методы математического динамического моделирования.

Результаты: одной из наиболее острых и нерешенных проблем для российской экономики является разработка такой валютно-денежной политики, которая бы обеспечивала возможности для экономического роста страны. Одной из причин продолжающихся споров является отсутствие качественной математической модели, позволяющей дать оценку ее влияния на экономические процессы. Рассмотрены математические модели, предложенные разными представителями экономической научной школы и описывающие влияние монетизации на экономику. Определено, что разработанные ранее модели мало применимы к экономике развивающихся стран. Дана характеристика математической модели динамического типа, разработанной авторами в рамках более ранних исследований, описывающая денежные потоки в российской экономике. Проанализирована значимость моделей для развивающихся экономик в условиях роста денежной массы и изменения курса национальной валюты. В результате определено, что построенная модель, являющаяся агрегированным вариантом модели переключающегося воспроизводства, учитывает открытость национальной экономики и инфляционные процессы. Модель протестирована на примере денежно-валютной политики США и России.

Научная новизна: модель отличается от аналогов тем, что в ее основе лежит моделирование денежных потоков в соответствии с методологией моделирования переключающегося воспроизводства, что позволяет анализировать взаимодействие финансового и реального секторов экономики в развивающихся странах.

Практическая значимость: модель позволяет оценивать последствия принимаемых решений в области валютноденежной политики в развивающихся странах.

Ключевые слова: экономика и управление народным хозяйством; математическое моделирование в экономике; валютно-денежная политика; механизмы монетизации; целевая эмиссия; инфляция; экономическое развитие развивающихся стран; макроэкономическое моделирование; динамическая модель

Благодарность: работа выполнена в рамках Государственного задания по теме «Феномен мезоуровня в экономическом анализе: новые теории и их практическое применение».

Конфликт интересов: авторами не заявлен. 
Как цитировать статью: Малков С. Ю., Давыдова О. И. Математическая модель для анализа взаимосвязи денежного обращения и экономического роста в развивающихся странах // Актуальные проблемы экономики и права. 2019. T. 13, № 1. C. 981-992. DOI: http://dx.doi.org/10.21202/1993-047X.13.2019.1.981-992

\author{
S. Yu. MALKOV', \\ O. I. DAVYDOVA ${ }^{2}$ \\ ${ }^{1}$ Institute of Economics of the Russian Academy of Sciences, Moscow, Russia \\ ${ }^{2}$ iDecide Consulting Ltd, Korolev
}

\title{
MATHEMATICAL MODEL FOR ANALYZING THE INTERRELATION BETWEEN MONETARY CIRCULATION AND ECONOMIC GROWTH IN DEVELOPING COUNTRIES
}

\author{
Contact: \\ Sergey Yu. Malkov, Doctor of Engineering, \\ Address: 32 Nakhimovskiy prosp., 117218, Moscow \\ E-mail: s@malkov.org \\ ORCID: https://orcid.org/0000-0002-9654-1439 \\ Researcher ID: http://www.researcherid.com/rid/L-5734-2015 \\ Olga I. Davydova, analyst, iDecide Consulting Ltd \\ Address: 6b Kalinin Str., 141070 Korolev, Moscow oblast \\ E-mail: davydova.olga.msk@gmail.com \\ ORCID: http://orcid.org/0000-0001-5308-3143 \\ Researcher ID: http://www.researcherid.com/rid/Q-2740-2018
}

Professor, Leading Researcher, Institute of Economics of the Russian Academy of Sciences

Objective: to develop a basic mathematical model to assess the impact of foreign trade on the national economy and the impact of the national currency on economic growth in relation to developing countries.

Methods: methods of mathematical dynamic modeling are used in the development of the model.

Results: one of the most acute and unresolved problems for the Russian economy is the development of such currencymonetary policy that would provide opportunities for economic growth. One of the reasons for the ongoing disputes is the lack of a qualitative mathematical model that allows assessing its impact on economic processes. Mathematical models proposed by representatives of different economic scientific schools and describing the impact of monetization on the economy are considered. It is determined that the previously developed models are not applicable to the economies of developing countries. The characteristic is given of the dynamic mathematical model earlier developed by the authors describing cash flows in the Russian economy. The importance of models for developing economies is analyzed in terms of growth of the money supply and changes in the exchange rate of the national currency. As a result, it is determined that the constructed model, which is an aggregate version of the model of switching reproduction, takes into account the openness of the national economy and inflation processes. The model is tested on the example of currency-monetary policy of the USA and Russia. Scientific novelty: the model differs from analogues in that it is based on the modeling of cash flows in accordance with the methodology of modeling of switching reproduction, which allows analyzing the interaction of financial and real sectors of economy in developing countries.

Practical significance: the model allows estimating the consequences of decisions in the field of currency-monetary policy in developing countries.

Keywords: Economics and national economy management; Mathematical modeling in economy; Currency-monetary policy; Mechanisms of monetization; Target emission; Inflation; Economic development of developing countries; Macroeconomic modeling; Dynamic model

Acknowledgement: the research is carried out as a part of State Order on the topic "Phenomenon of mesolevel in economic analysis: new theories and their practical application".

Conflict of Interest: No conflict of interest is declared by the authors.

Малков С. Ю., Давыдова О. И. Математическая модель для анализа взаимосвязи денежного обрашения и экономического роста.. Malkov S. Yu., Davydova O. I. Mathematical model for analyzing the interrelation between monetary circulation and economic growth... 
For citation: Malkov S. Yu., Davydova O. I. Mathematical model for analyzing the interrelation between monetary circulation and economic growth in developing countries, Actual Problems of Economics and Law, 2019, vol. 13, No. 1, pp. 981-992 (in Russ.). DOI: http://dx.doi.org/10.21202/1993-047X.13.2019.1.981-992

\section{Введение}

В условиях сложной ситуации в российской экономике, связанной с западными санкциями, низкой инвестиционной активностью и другими внешними и внутренними политическими факторами, не стихает дискуссия о мерах по преодолению имеющихся проблем, различными специалистами и организациями предлагаются рецепты ускорения экономического роста и соответствующие программы действий.

В частности, широко обсуждаются позиции А. Л. Кудрина [1] и С. Ю. Глазьева [2] по поводу рациональной денежной политики, опубликованы предложения «Столыпинского клуба» [3], среди которых уменьшение налоговой нагрузки на отечественный бизнес, стимулирование инвестиций, снижение ставки кредита, повышение монетизации экономики (в том числе посредством эмиссии денежных средств Центральным банком). Сторонники данных предложений ратуют за повышение регулирующей роли государства. Их противники считают, что предлагаемые меры спровоцируют инфляцию, нарушат рыночные механизмы и в конечном счете приведут к дестабилизации экономики. Данная дискуссия, к сожалению, приобрела политизированный характер и не дает результата.

Представляется, что причина такой тупиковой ситуации обусловлена тем, что к настоящему времени еще не разработан качественный методический аппарат количественного анализа и моделирования влияния валютно-денежной политики на экономическое развитие России. Целью настоящего исследования является продвижение в направлении совершенствования данного методического аппарата.

\section{Задача моделирования}

Актуальной проблемой экономической теории является создание математических моделей, позволяющих анализировать связь денежного обращения и экономического роста. Одним из первых, кто внес выдающийся вклад в этой области, был американский экономист Ирвинг Фишер, предложивший уравнение обмена [4], которое устанавливает зависимость между такими экономическими показателями, как денежная масса $M$ и скорость обращения денег $V$, с одной стороны и уровнем цен $P$ и объемами производства продукции $Q$ с другой:

$$
M \cdot V=P \cdot Q .
$$

Согласно уравнению Фишера, номинальный валовой внутренний продукт (далее - ВВП) (номинальная стоимость продукции и услуг $P \cdot Q$ ) равен произведению денежной массы и скорости обращения денег.

Спустя десятилетие английский экономист, основоположник теории рыночного ценообразования Альфред Маршалл предложил другую версию уравнения обмена. В основе его уравнения лежит коэффициент монетизации экономики, называемый также коэффициентом Маршалла, который отражает отношение денежной массы к ВВП [5]. Уравнение имеет следующий вид:

$$
M=k \cdot P \cdot Y,
$$

где $M$ - количество денег в обращении; $P$ - индекс цен на товары; $k$ - коэффициент монетизации экономики; $Y$ - валовой внутренний продукт. В уравнении Маршалла денежная масса зависит от уровня использования ВВП, т. е. от той части дохода, которая хранится в виде денег, а не используется в качестве инвестиций или с целью покупок товаров и услуг $[6,7]$.

Фишер и Маршалл на основе уравнений обмена оценивали эффект, который оказывало увеличение денежной массы на изменение цен по причине увеличения платежеспособного спроса или посредством создания безналичных денег (дополнительного кредита), что в свою очередь изменяло и процентную ставку.

Вопросом процентной ставки также продолжительное время занимался шведский экономист Кнут Викселль, разделивший понятия натурального процента, на который влияет прибыльность капитала, и денежного процента, зависящего от спроса и предложения денег [8].

Большой вклад в теорию монетизации внес английский экономист Джон Кейнс. В 1936 г. была опубли- 
кована его работа «Общая теория занятости, процента и денег» [9]. В ней утверждалось, что в экономике деньги не играют значительную роль, основная задача - добиться полной занятости. Полная занятость не может быть достигнута только за счет рыночных механизмов, поскольку совокупное предложение больше совокупного спроса по причине наличия сбережений. Поэтому требуется государственное регулирование экономики для увеличения спроса посредством изменения процентной ставки или количества денег. Многие развитые страны на протяжении десятилетий эффективно использовали данную схему.

Кейнс вводит зависимость спроса на денежную массу от совокупного дохода и процентной ставки:

$$
M^{d}=L(Y, r),
$$

где $Y$ - совокупный доход; $r$ - процентная ставка.

Далее исследованием зависимости спроса на денежную массу занимался Милтон Фридман. В функцию (3) он добавил дополнительные переменные, включая активы, позволяющие получить доход, а также инвестиции в человеческий капитал [10-15]. На основе данных США по уровню цен и денежной массы за продолжительный период времени Фридман приходит к выводу, что спрос на деньги определяется только совокупным доходом. Кроме того, Фридман показывает, что для устойчивой экономической системы необходимо постоянное равномерное увеличение количества денег.

В 1937 г. была опубликована работа Джона Хикса «Господин Кейнс и "классики". Попытка интерпретации» [16]. Принимая во внимание исследования Кнута Викселля, Хикс создает модель экономики, содержащую как денежный сектор, так и реальный, в которых задана процентная ставка. Денежный сектор определяет спрос и предложение, реальный - сбережения и вложения. Хикс показал, что процентная ставка формируется в реальном секторе и в то же время в денежном секторе. Артур Пигу, также занимавшийся изучением спроса, показывает, что при изменении денежной массы спрос тоже меняется. Он вводит понятие «эффекта богатства», т. е. увеличения внутреннего валового продукта и занятости под влиянием увеличенного спроса при росте благосостояния [17].

На основе выводов, полученных Хиксом и Пигу, Дон Патинкин предложил усовершенствованную макроэкономическую модель, в которой рассматри- вается взаимное влияние нескольких рынков экономики (рынок товаров, рынок труда, рынок облигаций и рынок денег) посредством динамики цен или динамики ставки процента [18]. В работе «Некоторые направления эволюции денежной теории» предложена модификация модели Патинкина и ее верификация на статистических данных России и Казахстана [19].

К началу 1960-х гг. появилось много монетарных теорий, которые на основе статистических данных опровергали кейнсианские идеи о том, что деньги не оказывают существенного влияния на экономику. Проводятся различные исследования по выявлению зависимостей между денежной массой, номинальным доходом и инфляцией [20-24]. Фридман на основе статистических данных США за 100 лет доказывает взаимосвязь между номинальным доходом и денежной массой [10-15]. К. Варбуртон также опубликовал несколько работ, в которых рассматривал влияние денежной массы на экономику. Варбуртон показал, что при увеличении денежной массы растет инфляция и происходят колебания реального ВВП [25].

Л. Андерсен и Д. Джордан, специалисты Резервного Банка Сент-Луиса в США, в 1968 г. представили модель, позволяющую производить оценку государственной экономической политики [26]. Экономисты рассматривали взаимосвязь между номинальным доходом, денежной массой и налогово-бюджетной политикой. В ходе исследования выяснилось, что денежная масса не только определяет номинальный доход и влияет на валовой национальный продукт за небольшой интервал времени, но и оказывает гораздо большее влияние, чем налогово-бюджетная политика.

Андерсен и Карлсон продолжили исследования в данной области и в 1970 г. предложили «монетаристскую модель экономической стабилизации» («сент-луисскую модель») [27]. Модель состояла из нескольких базовых уравнений, с помощью которых оценивалось влияние денежной массы на реальный внутренний валовой продукт, процентные ставки и безработицу. Модель также показала эффективность кредитно-денежной политики в экономике.

В последние десятилетия при анализе объемов и структуры денежных агрегатов и при исследовании процессов монетизации широко используются экономико-статистические и регрессионные методы. Достоинством этих методов является то, что с их помощью можно выявить факторы, условия и основные 
тенденции функционирования денежного рынка, а также определить основные способы его регулирования средствами валютно-денежной политики. Но, как показывает анализ, разработанные экономикостатистические модели адаптированы к решению проблем в развитых странах и плохо применимы к развивающимся странам, монетизация экономики которых определяется в основном притоком валюты в страну от экспортных операций.

В связи с этим необходима разработка макроэкономической модели, предназначенной для анализа различных механизмов монетизации экономики развивающихся стран и позволяющей определять меры валютно-денежной политики, стимулирующие экономический рост и минимизирующие инфляцию.

\section{Описание модели}

Ранее для моделирования процессов монетизации в РФ авторами была предложена математическая модель динамического типа [28], которая описывала денежные потоки в российской экономике, отображенные на рисунке.

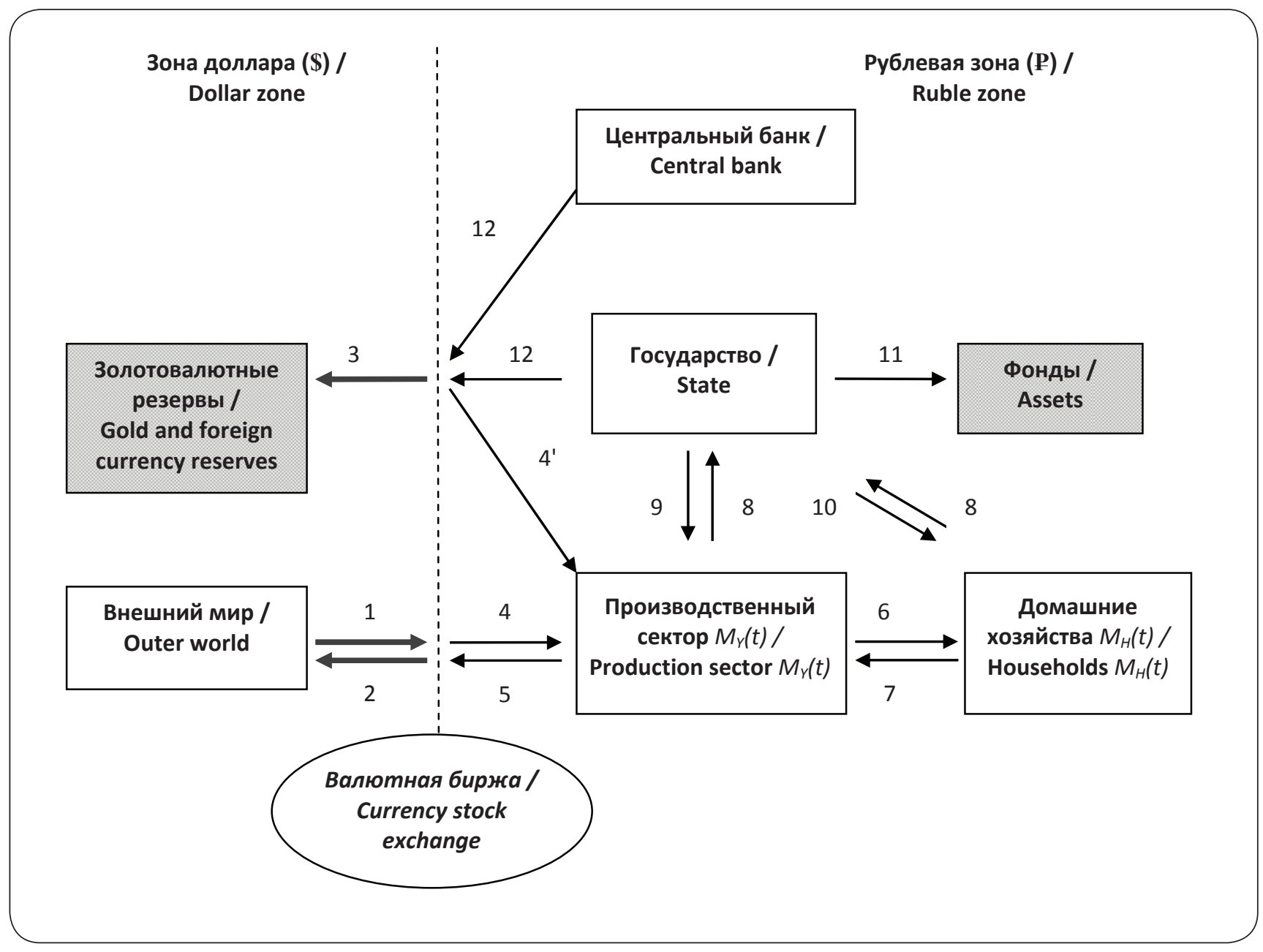

Обобщенная схема денежных потоков

(стрелками обозначены потоки денег, штриховой линией - валютная граница)*

* Источник: [28, с. 20].

Generalized scheme of monetary flows

(arrows indicate monetary flows, the dashed line indicates a currency border)*

* Source: $[28$, p. 20]. 
Логика рассуждений, использованная в модели [28], была применена для более общего случая моделирования взаимосвязи денежного обращения и экономического роста в развивающихся странах, для которых трансграничные торговые и денежные потоки играют большую роль (к этим странам относится и Россия). При этом структура уравнений была откорректирована с учетом результатов моделирования денежных потоков на основе модели переключающегося режима воспроизводства (ПРВ), изложение которой содержится в работах [29-32]. Преимуществом модели ПРВ является то, что она описывает взаимодействие:

- денежных потоков, возникающих в ходе производства и потребления потребительской продукции, а также в ходе воспроизводства основного капитала (быстрый и медленный контур денежного обращения);

- финансового сектора с реальным производством.

Это позволяет увидеть связь денежной политики, осуществляемой в рассматриваемой стране, с экономическим ростом и инфляционными процессами.

Реальный сектор в модели ПРВ состоит из макроэкономических подсистем $\left\{G_{1}, G_{2}, \ldots, G_{N}\right\}$, которые поочередно обновляют свой основной капитал. При этом происходит периодическое переключение подсистем с программы В (производство товаров и услуг на потребительский рынок) на программу А (воспроизводство основного капитала) и обратно. Домашние хозяйства (ДХ) разделены на $N$ групп: каждой подсистеме соответствует своя группа домашних хозяйств. В работах [29-31] представлены результаты использования модели ПРВ для анализа закрытой экономики (когда взаимодействие с внешним миром не играет определяющей роли). В работе [32] описана открытая базовая модель ПРВ, в которой в обобщенном виде учитывается взаимодействие национальной экономики с внешним миром.

В случае развивающихся стран взаимодействие с внешним миром играет важную роль и для функционирования реального сектора экономики (в силу его зависимости от импортных технологий ${ }^{1}$, и при определении приоритетов валютно-денежной политики (в силу зависимости внешнеторгового баланса и инфляционных процессов от курса национальной валюты $^{2}$ ). В соответствии с этим встает задача создания

\footnotetext{
1 Эта зависимость в модели [28] в явном виде не учитывалась.

2 Эта зависимость не учитывалась в явном виде в модели ПРВ.
}

математической динамической модели для анализа связи денежного обращения и экономического роста в развивающихся странах с учетом внешнеторговых связей и проводимой валютно-денежной политики. Схема денежных потоков в экономиках таких стран аналогична схеме, представленной на рисунке, с тем отличием, что в нее дополнительно необходимо добавить поток от актора «Центральный банк» к актору «Государство». Пояснение к схеме, с учетом [28, c. 20-21], следующее:

«1) основными экономическими акторами, изображенными на схеме, являются: производственный сектор (ПС), домашние хозяйства (ДХ), государство (Г), изентральный банк (ЦБ), внешний мир;

2) к потокам валютных средств относятся: экспортная выручка (1), оплата импорта (2), увеличение золотовалютных резервов (ЗВР) (3);

3) к потокам рублевых средств относятся: экспортная выручка (4, 4'), доходы домашних хозяйств (6), потребление домашних хозяйств (7), налоги (8), госзакупки и субсидии (9), зарплаты бюджетникам и социиальные трансферты (пенсии, стипендии и др.) (10), пополнение фондов Правительства (11), покупка валюты и увеличение ЗВР (12), финансирование дефицита государственного бюджета (посредством покупки Центральным банком государственных иенных бумаг).

Описание базовых процессов на валютной границе (соответственно, на валютной бирже):

- основной источник притока иностранной валють (долларов) на валютную граничу - валютная выручка экспортеров: экспортеры часть своей валютной выручки конвертируют в национальную валюту для проведения финансовых операций внутри страны и выллаты налогов;

- спрос на иностранную валюту на валютной бирже формируют импортеры (она нужна им для покупки импортных товаров за рубежсом), а также фирмы и население, которые часть своих средств хотят хранить на валютных депозитах и в виде наличных долларов (евро). Кроме того, государство формирует денежные фонды, часть которых хранится на валютных счетах;

- в ходе торгов на валютной бирже на основе спроса

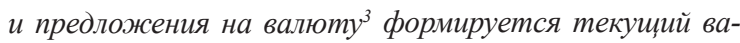
лютный курс национальной валюты. Центральный банк с помощьюю различных инструментов (включая прямые валютные интервенции) контролирует ход торгов и влияет на формирование курса национальной валюты. Кроме того, Центральный банк проводит закупки долларов (евро) для пополнения золотовалютных резервов (ЗВР)».

\footnotetext{
3 Кроме перечисленных выше фундаментальных экономических процессов, на спрос и предложение валюты влияют также валютные спекулянты, которые косвенно учитываются в модели.
} 
Как указывалось выше, для математического описания денежных потоков в национальной экономике (с учетом потоков, отображенных на рисунке, стр. 985), целесообразно использовать логику моделирования, использованную в модели ПРВ [29-32]. Доработки по отношению к модели ПРВ заключаются, с одной стороны, в расширении модели с целью учета открытости экономики и учета инфляционных процессов, с другой стороны, в агрегировании модели. Агрегирование выражается в объединении всех макроэкономических подсистем в единый «производственный сектор» (ПС), а также в объединении государства и домашних хозяйств в единый «общественный сектор» (ОС). Объединение государства и ДХ в один сектор сделано с целью улучшения качества калибровки модели с использованием данных макроэкономической статистики.

В обобщенном виде денежные потоки, отраженные на рисунке, могут быть описаны следующими дифференциальными уравнениями, аналогичными дифференциальным уравнениям из работы [28].

Уравнение для динамики денежных средств производственного сектора $M_{Y}(t)$ :

$$
\frac{d M_{Y}(t)}{d t}=
$$

= (доходы от продажи товаров и услуг внутри страны, субсидии) -

- (выплаты домашним хозяйствам, налоги государству) +

+ (доходы от экспорта) - (расходы на импорт) +

+ (другие денежные потоки).

Уравнение для динамики денежных средств общественного сектора $M_{H}(t)$ :

$$
\frac{d M_{h}(t)}{d t}=
$$

$=($ доходы домашних хозяйств, налоги ПС) -

- (расходы домашних хозяйств) -

- (государственные закупки, субсидии ПС) +

$$
\text { + (другие денежные потоки). }
$$

Уравнение для динамики уровня цен $p(t)$ (описывает установление цены на основе баланса спроса и предложения товаров и услуг на внутреннем рынке):

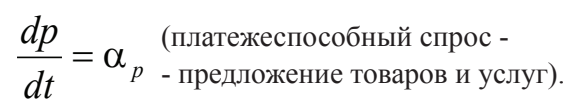

Уравнение для динамики курса доллара $b(t)$ (описывает установление курса валюты на основе баланса спроса на доллары и их предложения на валютном рынке):

$$
\frac{d b}{d t}=\alpha_{b} \text { (спрос на валюту - предложение валюты) }
$$

С учетом достаточно общих допущений модель (3)-(6) может быть записана в виде:

$$
\begin{gathered}
\frac{d M_{Y}}{d t}=k_{H} \cdot M_{H}-\Delta M_{b e}-h \cdot F \cdot p+ \\
+Q_{E} \cdot p^{\prime} \cdot b-k_{Y I} \cdot M_{Y}-k_{H I} \cdot M_{H}+\Delta M_{Y},
\end{gathered}
$$

где $\left(k_{H} M_{H}-\Delta M_{b e}\right)-$ поток денежных средств из ОС в ПС, включающий доходы от продажи товаров и услуг внутри страны, субсидии (в модели считается, что они пропорциональны денежным средствам ОС с учетом того, что часть средств $\Delta M_{b e}$ сектор ОС расходует на покупку иностранной валюты); $h F p$ - поток денежных средств из ПС в ОС, включающий выплаты домашним хозяйствам, налоги государству (в модели считается, что они пропорциональны номинальному ВВП $F p^{4}$ ); $Q_{E} p^{\prime} b$ - доходы от экспорта в национальной валюте $\left(Q_{E}-\right.$ физический объем экспорта, $Q_{E} p^{\prime}-$ стоимость экспорта в долларах, $b-$ курс доллара, т. е. сколько единиц национальной валюты отдают за один доллар); $k_{Y I} M_{Y}$ - расходы на закупку производственного импорта: оборудования, технологий, комплектующих, сырья (в модели считается, что эти расходы пропорциональны средствам ПС); $k_{H I} M_{H}$ - расходы на закупку импортной потребительской продукции (в модели считается, что они определяются потребительским денежным спросом и пропорциональны средствам $\mathrm{OC}) ; \Delta M_{Y}$ - другие денежные потоки (например, дополнительное субсидирование ПС за счет дефицита государственного бюджета);

$$
\frac{d M_{H}}{d t}=h \cdot F \cdot p-k_{H} \cdot M_{H}+\Delta M_{H},
$$

где $h F p$ - поток денежных средств из ПС в ОС, включающий доходы домашних хозяйств, налоги ПС (см. выше); $k_{H} M_{H}$ - потребительские расходы ДХ (включая расходы на импорт ${ }^{5}$ ), государственные закупки, субсидии ПС (в модели считается, что эти расходы

${ }^{4}$ Выражение для производственной функции $F$ приведено ниже.

5 В модели считается, что импортная потребительская продукция закупается за рубежом производственным сектором, который уже затем продает ее отечественным потребителям на внутреннем рынке. 
пропорциональны денежным средствам ОС); $\Delta M_{H}-$ другие денежные потоки (например, дополнительное субсидирование ОС за счет дефицита государственного бюджета);

$$
\frac{d p}{d t}=\alpha_{p} \cdot p \cdot\left(\frac{k_{H} \cdot M_{H}-k_{H I} \cdot M_{H}}{F \cdot p-\left(k_{Y}-k_{Y I}\right) M_{Y}-Q_{E} \cdot p}-1\right),
$$

где числитель дроби в скобках отражает денежный спрос на отечественную продукцию; знаменатель предложение отечественной продукции (стоимостное выражение всей произведенной продукции за вычетом продукции инвестиционного назначения и продукции, произведенной на экспорт); $\alpha_{p}-$ коэффициент, характеризующий скорость установления ценового равновесия на внутреннем рынке;

$$
\frac{d b}{d t}=\alpha_{b} \cdot b \cdot\left(\frac{k_{H I} \cdot M_{H}+k_{Y I} \cdot M_{Y}+\Delta M_{b e}+\Delta M_{b c}}{Q_{E} \cdot p^{\prime} \cdot b}-1\right),
$$

где числитель в скобках отражает денежный спрос на доллары (в него входит стоимость закупки импортной продукции, спрос на закупку валюты со стороны сектора ОС $\Delta M_{b e}$ и валютные интервенции Центрального банка $\left.\Delta M_{b c}\right)$; знаменатель отражает предложение долларов (соответствует валютной выручке за экспортируемую продукцию); $\alpha_{b}-$ коэффициент, характеризующий скорость установления равновесия на валютном рынке.

Используя результаты работы [33], выражение для производственной функции $F$ можно представить в виде:

$$
F=f \cdot\left(\frac{k_{Y} \cdot M_{Y}}{p}-\frac{k_{Y I} \cdot M_{Y}}{p}\left(1-\frac{w}{b}\right)\right)^{c},
$$

где $k_{Y} M_{Y}-$ общие расходы на инвестиции (в модели считается, что они пропорциональны денежным средствам ПС); $k_{Y I} M_{Y}$ - расходы на импортную инвестиционную продукцию (в модели считается, что они пропорциональны денежным средствам ПС); $w$ - коэффициент эффективности импортной инвестиционной продукции; $c$ - коэффициент, характеризующий убывающую/возрастающую отдачу от инвестиций; $f$ - коэффициент пропорциональности.

Необходимо отметить, что модель (7)-(11) имеет базовый характер и предназначена для анализа общих закономерностей экономической динамики развивающихся стран. Некоторые из этих закономерностей рассмотрены ниже.

\section{Результаты моделирования}

Приступая к анализу модели (7)-(11) и получаемых с ее помощью результатов, надо сначала убедиться, что она согласуется с ранее предложенными теоретическими моделями. Действительно, если рассматривать ситуацию, близкую к равновесной 6 , когда правые части уравнений (7)-(11) можно считать равными нулю, а государственный бюджет сбалансирован, то уравнение (8) преобразуется к виду:

$$
\begin{aligned}
& M_{H} \cdot\left(h / k_{H}\right)=p \cdot F \\
& \text { или } \\
& M_{H}=\left(k_{H} / h\right) \cdot p \cdot F .
\end{aligned}
$$

Видно, что уравнение (12) является прямым аналогом уравнения (1), предложенного И. Фишером, а уравнение (13) - прямым аналогом уравнения (2), предложенного А. Маршаллом. Можно показать, что более поздние модели, обзор которых приведен выше, также согласуются с системой (7)-(11).

Серьезной проблемой для развивающихся стран является проблема повышения уровня монетизации их экономик (такая проблема сейчас стоит и перед Россией, по ее поводу идут острые дискуссии [1-3]). Однако модели (1) и (2) не дают внятного ответа на вопрос, какими будут последствия увеличения денежной массы, осуществляемого путем, например, дополнительной денежной эмиссии, поскольку в соответствии с (1) и (2) эмиссия может привести как к увеличению реального ВВП ( $Q$ и $Y$ в моделях (1) и (2) соответственно), так и к увеличению инфляции (уровня цен $P$ ). Модель (7)(11) показывает, что основными факторами, определяющими характер влияния монетизации на реальный ВВП, является вид производственной функции (прежде всего, величина коэффициента $c$ в уравнении (11), характеризующего значение убывающей/возрастающей отдачи от увеличения масштабов производства ${ }^{7}$ ), а также соотношение между накоплением и потреблением (в модели это соотношение зависит прежде всего от значения коэффициента $h$ ).

Моделирование показывает, что дополнительная денежная эмиссия порождает как инфляцию (увели-

\footnotetext{
6 Такие ситуации рассматриваются в широко распространенных моделях общего равновесия ( $C G E$-моделях).

7 Убывающая/возрастающая отдача-это структурная характеристика конкретной национальной экономики, величина которой определяется на основе анализа экономической статистики.
} 
чение $P$ ), так и экономический рост (увеличение $Q$ ), при этом соотношение $P / Q$ будет тем больше, чем меньше коэффициент $c$ и больше коэффициент $h$.

Для развивающихся стран важную роль играют механизмы монетизации экономики. В экспортно ориентированных странах, торгующих сырьем (как, например, РФ) или продукцией конечного потребления (как, например, КНР) и имеющих положительное торговое сальдо (т. е. $Q_{E} p^{\prime} b-k_{Y I} M_{Y}-k_{H I} M_{H}>0$ ), в соответствии с уравнением (10) происходит укрепление национальной валюты ${ }^{8}$ (в модели это выражается в уменьшении значения $b$ ). Следствием этого является уменьшение доходов экспортеров в национальной валюте $\left(Q_{E} p^{\prime} b\right)$ и снижение ценовой конкурентоспособности экспортных товаров на внешних рынках (поскольку закладываемые в цену производственные издержки с повышением курса национальной валюты тоже начинают расти). Это так называемая «голландская болезнь», ведущая к стагнации экономики.

Снижение курса национальной валюты возможно, если Центральный банк будет активно скупать «избыточную» иностранную валюту на валютном рынке (это означает увеличение значения $\Delta M_{b c}$ в уравнении (10)) и наполнять ею золотовалютные резервы. При этом происходит дополнительная денежная эмиссия и повышение монетизации национальной экономики, что в целом оказывает на нее благотворное влияние.

Однако избыточная денежная эмиссия в условиях убывающей отдачи приводит к росту инфляции. Кроме того, снижение курса национальной валюты уменьшает возможности закупки высокотехнологичного оборудования за рубежом (см. последний член в уравнении (11), где величина $b$ стоит в знаменателе), что снижает возможности экономического развития.

Таким образом, возникает задача поиска золотой середины в реализации валютно-денежной политики. Модель (7)-(11), отражающая описанные эффекты, предназначена для поиска этой золотой середины применительно к конкретной стране и конкретной макроэкономической ситуации.

\section{Пример анализа процесса монетизации}

Рассмотрим различие процесса монетизации в развитых и развивающихся странах (на примере США и России).

\footnotetext{
8 При условии $\Delta M_{b e}, \Delta M_{b c} \approx 0$.
}

В США денежная эмиссия осуществляется в интересах обеспечения экономического роста. С этой целью Федеральная резервная система (ФРС) регулирует ключевую ставку и норму резервирования, а также покупает казначейские облигации. Государственный долг США при этом растет, но экономика насыщается деньгами.

В отличие от США монетизация российской экономики напрямую зависит от валютных доходов от экспорта (главным образом экспорта нефти и газа). Когда цены на углеводородное сырье были высокими, предложение нефтегазовых долларов на валютной бирже превышало спрос. Центральный банк скупал избыточные доллары, не давая повышаться курсу рубля. Это требовало дополнительной эмиссии рублей. Эмитированные рубли поступали экспортерам и через них попадали в экономику, что приводило к росту денежной массы М2. Поэтому в 2001-2008 гг., когда цены на нефть росли, денежная масса М2 тоже росла высокими темпами (на 30-40 \% в год). В последующем, когда цены на нефть снизились в несколько раз, данный канал монетизации фактически перестал действовать. Более того, началась демонетизация российской экономики и торможение ее роста.

При снижении валютной выручки нужны альтернативные механизмы повышения монетизации экономики РФ, например, посредством выпуска государственных облигаций и запуска масштабных инфраструктурных проектов, а также путем повышения возможностей кредитования экономики через увеличение Центральным банком России корреспондентских счетов коммерческих банков. Однако Центральный банк с 2015 г. пошел по пути повышения ключевой ставки, сжатия денежной массы и таргетирования инфляции. Дискуссии о том, насколько правилен этот курс, продолжаются до настоящего времени. Для разрешения этих споров необходимо привлечение методов математического моделирования.

Для анализа подобных ситуаций может быть использована модель (7)-(11). Рассчитывались два сценария:

1) в первом денежная масса $M 2$ замораживалась на уровне 2015 г. и считалось, что экспорт равен импорту;

2) во втором сценарии экспорт тоже был равен импорту, но при этом предполагалось, что Центральный банк покупает государственные облигации (по примеру ФРС США) и тем самым увеличивает монетизацию 
экономики. Получаемые от продажи облигаций рублевые средства государство целевым образом направляет в обрабатывающие отрасли промышленности.

Значения коэффициентов модели определялись на основе стандартной процедуры идентификации параметров с использованием рядов макроэкономических статистических данных, предоставляемых Росстатом.

Результаты расчета по первому сценарию показывают, что заморозка денежной массы приводит к снижению инфляции, но и к снижению реального ВВП 9 . Расчет по второму сценарию показывает, что целевая эмиссия с 2016 г. в обрабатывающий сектор могла бы привести к росту реального ВВП при умеренной инфляции ${ }^{10}$. Таким образом, вопрос заключается в определении конкретных объемов и каналов монетизации для обеспечения экономического роста при контроле над инфляцией. Оптимальное решение этого вопроса возможно при использовании математического моделирования с использованием моделей типа той, что изложена в данной статье.

\section{Выводы}

В статье приведено описание базовой теоретической динамической модели, являющейся агрегированным вариантом модели переключающегося воспроизводства, в которой учитывается открытость национальной экономики и инфляционные процессы в соответствии с алгоритмом, использованным в нашей более ранней работе [28]. Кроме того, в модели в явном виде учтены затраты на закупку импортного оборудования и технологий, а также показатели эффективности их использования, имеющие важное значение для экономики развивающихся стран. Модель предназначена для оценки влияния внешней торговли на экономику развивающихся стран, влияния курса национальной валюты на экономический рост и последствия различных управленческих решений в области валютно-денежной политики. В дальнейшем разработанная модель будет адаптирована к статистике конкретных развивающихся стран с целью анализа их экономической динамики.

\section{Список литературы}

1. Кудрин А. Л., Горюнов Е. Л., Трунин П. В. Стимулирующая денежно-кредитная политика: мифы и реальность // Вопросы экономики. 2017. № 5. С. 5-28.

2. Глазьев С. Ю. Нищета и блеск российских монетаристов. Ч. 2 // Экономическая наука современной России. 2015. № 3 (70). С. 7-25.

3. Титов Б. Ю. и др. Среднесрочная программа социально-экономического развития страны до 2025 года «Стратегия роста». М.: Институт экономики роста им. П. А. Столыпина, 2017.

4. Фишер И. Покупательная сила денег. М.: Дело, 2001 (1911). 320 с.

5. Греков И. Е. О совершенствовании подходов к определению монетизации экономики и обоснование ее оптимального уровня // Финансы и кредит. 2007. № 11. С. 60-70.

6. Греков И. Е. Об определении монетизации экономики и ее оптимальном уровне // Управление общественными и экономическими системами. 2006. № 3. С. 52-61.

7. Marshall A. Money, Credit and Commerce. Macmillan, London, 1923. Pp. 369.

8. Wicksell K. Lectures on political economy. Ludwig von Mises Institute, 1967. Vol. 1. 326 p.

9. Кейнс Дж. М. Общая теория занятости, процента и денег. Избранное. М.: Эксмо, 2007. 960 с. ISBN 978-5-699-20989-7.

10. Studies in the quantity theory of money / ed. M. Friedman. University of Chicago Press, 1956. Vol. 561.

11. Friedman M. A theoretical framework for monetary analysis // Journal of Political Economy. 1970. Vol. 78. № 2. Pp. 193-238.

12. Friedman M. The Role of Monetary Policy // American Economic Review. 1968. № 58. Pp. 1-17.

13. Friedman M., Meiselman D. The Relative Stability of Monetary Velocity and the Investment Multiplier in the United States, 1897-1958 // Stabilization Policies / Prentice-Hall, Englewood, 1963. Pp. 165-268.

14. Friedman M., Schwartz A. J. A Monetary History of the United States. Princeton University Press, 1963. 888 p.

15. Brunner K., Friedman M. Studies in the Quantity Theory of Money. 1957.

\footnotetext{
9 Реально в последние годы рост денежной массы происходил, но небольшими темпами (6-7 \% в год).

${ }^{10}$ Полученные результаты соответствуют результатам работы [28], что косвенно подтверждает их правильность.
} 
16. Hicks J. R. Mr. Keynes and the «Classics»; A Suggested Interpretation // Econometrica. 2018. Vol. 5, № 2. Pp. $147-159$. DOI: $10.2307 / 1907242$

17. Pigou A. C. The Classical Stationary State // Economic Journal. 1943. Vol. 53. № 212. Pp. 343-351.

18. Hood W. Money, Interest, and Prices: An Integration of Monetary and Value Theory. By Don Patinkin. Evanston, Ill., and White Plains, N.Y.: Row, Peterson and Company. 1956. Pp. xx, 510 // Canadian Journal of Economics and Political Science, 1958. Vol. 24, № 1. Pp. 127-130.

19. Маневич В. Е., Сабранов У. К., Некоторые направления эволюции денежной теории // Экономическая наука современной России. 2001. № 4. С. 38-51.

20. Cagan P. The Monetary Dynamics of Hyperinflation // Studies in the Quantity Theory of Money / ed. M. Friedman. The University of Chicago Press, Chicago, 1956. Pp. 25-117.

21. Frenkel J. A. Inflation and the Formation of Expectations // Journal of Monetary Economics. 1976. Vol. 1, № 4. Pp. 403-421.

22. Goldman S. M. Hyperinflation and the Rate of Growth in the Money Supply // Journal of economic theory. 1972. Vol. 5 , № 2. Pp. 250-257.

23. Hadjimichalakis M. Money, expectations, and dynamics-an alternative view // International Economic Review. 1971. Pp. 381-402.

24. Sidrauski M. Inflation and economic growth // The Journal of Political Economy. 1967. Pp. 796-810.

25. Warburton C. Depression, inflation, and monetary policy: selected papers, 1945-1953. Johns Hopkins University Press, 1966. $425 \mathrm{p}$.

26. Andersen L. C., Jordan J. L. Monetary and Fiscal Actions: A Test of Their Relative Importance in Economic Stabilization // St. Louis Federal Reserve Bank Review. 1968. Vol. 50, № 1. Pp. 1-20.

27. Andersen L. C. et al. A monetarist model for economic stabilization. Federal Reserve Bank of St. Louis, 1970. P. 22.

28. Малков С. Ю., Билюга С. Э., Давыдова О. И. Монетизация российской экономики: возможности математического моделирования // Экономика и управление: проблемы, решения. 2016. Т. 2, № 7. С. 17-24.

29. Маевский В. И., Малков С. Ю., Рубинштейн А. А. Об эволюции моделей переключающегося режима воспроизводства // Актуальные проблемы экономики и права. 2018. Т. 12, № 4. С. 816-827.

30. Денежные механизмы и модель переключающегося режима воспроизводства / В. И. Маевский, С. А. Андрюшин, С. Ю. Малков, А. А. Рубинштейн // Вопросы экономики. 2016. № 9. С. 129-149.

31. Маевский В. И., Малков С. Ю., Рубинштейн А. А. Анализ экономической динамики США, СССР и России с помощью модели ПРВ // Вопросы экономики. 2018. № 7. С. 82-95.

32. Маевский В. И., Малков С. Ю., Рубинштейн А. А. Новая теория воспроизводства капитала: развитие и практическое применение. М.; СПб.: Нестор-История, 2016. 260 с.

33. Малков С. Ю., Давыдова О. И., Билюга С. Э. Макроэкономическая производственная функция: эмпирический межстрановый анализ // Анализ и моделирование мировой и страновой динамики: экономические и политические процессы / отв. ред. С. Ю. Малков, Л. Е. Гринин. М.: Московская редакция издательства «Учитель», 2016. С. 7-26.

\section{References}

1. Kudrin A. L., Goryunov E. L., Trunin P. V. Stimulating monetary-credit policy: myths and reality, Voprosy ekonomiki, 2017, No. 5, pp. 5-28 (in Russ.).

2. Glaz'ev S. Yu. Splendors and miseries of the Russian monetarists, Part. 2, Ekonomicheskaya nauka sovremennoi Rossii, No. 3 (70), 2015, pp. 7-25 (in Russ.).

3. Titov B. Yu. et al. Mid-term program of the social-economic development of Russia up to 2025 "Strategy of growth", Moscow, Institut ekonomiki rosta im. P. A. Stolypina, 2017 (in Russ.).

4. Fisher I. The Purchasing Power of Money: Its determination and relation to credit, interest and crises, Moscow, Delo, 2001 (1911), 320 p. (in Russ.).

5. Grekov I. E. On improving approaches to defining economics monetization and substantiating its optimal level, Finansy i kredit, 2007, No. 11, pp. 60-70 (in Russ.).

6. Grekov I. E. On defining economics monetization and its optimal level, Upravlenie obshchestvennymi i ekonomicheskimi sistemami, 2006, No. 3, pp. 52-61 (in Russ.).

7. Marshall A. Money, Credit and Commerce, Macmillan, London, 1923, pp. 369.

8. Wicksell K. Lectures on political economy, Ludwig von Mises Institute, 1967, Vol. 1, 326 p.

9. Keynes J. M. The General Theory of employment, Interest and Money. Selected Works, Moscow, Eksmo, 2007,960 p. ISBN 978-5-699-20989-7 (in Russ.). 
10. Studies in the quantity theory of money, ed. M. Friedman, University of Chicago Press, 1956, Vol. 561.

11. Friedman M. A theoretical framework for monetary analysis, Journal of Political Economy, 1970, Vol. 78, No. 2, pp. $193-238$.

12. Friedman M. The Role of Monetary Policy, American Economic Review, 1968, No. 58, pp. 1-17.

13. Friedman M., Meiselman D. The Relative Stability of Monetary Velocity and the Investment Multiplier in the United States, 1897-1958, Stabilization Policies, Prentice-Hall, Englewood, 1963, pp. 165-268.

14. Friedman M., Schwartz A. J. A Monetary History of the United States, Princeton University Press, 1963, 888 p.

15. Brunner K., Friedman M. Studies in the Quantity Theory of Money, 1957.

16. Hicks J. R. Mr. Keynes and the "Classics"; A Suggested Interpretation, Econometrica, 2018, Vol. 5, No. 2, pp. $147-159$. DOI: $10.2307 / 1907242$

17. Pigou A. C. The Classical Stationary State, Economic Journal, 1943, Vol. 53, No. 212, pp. 343-351.

18. Hood W. Money, Interest, and Prices: An Integration of Monetary and Value Theory. By Don Patinkin. Evanston, Ill., and White Plains, N.Y.: Row, Peterson and Company. 1956. Pp. xx, 510, Canadian Journal of Economics and Political Science, 1958, Vol. 24, No. 1, pp. 127-130.

19. Manevich V. E., Sabranov U. K., Nekotorye napravleniya evolyutsii denezhnoi teorii, Ekonomicheskaya nauka sovremennoi Rossii, 2001, No. 4, pp. 38-51 (in Russ.).

20. Cagan P. The Monetary Dynamics of Hyperinflation, Studies in the Quantity Theory of Money, ed. M. Friedman, The University of Chicago Press, Chicago, 1956, pp. 25-117.

21. Frenkel J. A. Inflation and the Formation of Expectations, Journal of Monetary Economics, 1976, Vol. 1, No. 4, pp. $403-421$.

22. Goldman S. M. Hyperinflation and the Rate of Growth in the Money Supply, Journal of economic theory, 1972, Vol. 5, No. 2, pp. 250-257.

23. Hadjimichalakis M. Money, expectations, and dynamics-an alternative view, International Economic Review, 1971, pp. 381-402.

24. Sidrauski M. Inflation and economic growth, The Journal of Political Economy, 1967, pp. 796-810.

25. Warburton C. Depression, inflation, and monetary policy: selected papers, 1945-1953, Johns Hopkins University Press, $1966,425 \mathrm{p}$.

26. Andersen L. C., Jordan J. L. Monetary and Fiscal Actions: A Test of Their Relative Importance in Economic Stabilization, St. Louis Federal Reserve Bank Review, 1968, Vol. 50, No. 1, pp. 1-20.

27. Andersen L. C. et al. A monetarist model for economic stabilization, Federal Reserve Bank of St. Louis, 1970, p. 22.

28. Malkov S. Yu., Bilyuga S. E., Davydova O. I. Monetization of he Russian economy: capabilities of mathematical modeling, Ekonomika i upravlenie: problemy, resheniya, 2016, Vol. 2, No. 7, pp. 17-24 (in Russ.).

29. Maevsky V. I., Malkov S. Yu., Rubinstein A. A. On the evolution of switching reproduction models, Actual problems of economics and law, 2018, Vol. 12, No. 4, pp. 816-827 (in Russ.).

30. Maevsky V. I., Andryushin S. A., Malkov S. Yu., Rubinstein A. A. Monetary mechanisms and switching reproduction model, Voprosy ekonomiki, 2016, No. 9, pp. 129-149 (in Russ.).

31. Maevsky V. I., Malkov S. Yu., Rubinstein A. A. Analysis of economic dynamics of the USA, the USSR and Russia with switching reproduction model, Voprosy ekonomiki, 2018, No. 7, pp. 82-95 (in Russ.).

32. Maevsky V. I., Malkov S. Yu., Rubinstein A. A. New theory of capital reproduction: development and practical application, Moscow; Saint Petersburg, Nestor-Istoriya, 2016, 260 p. (in Russ.).

33. Malkov S. Yu., Davydova O. I., Bilyuga S. E. Macroeconomic production function: empirical inter-state analysis, Analiz i modelirovanie mirovoi i stranovoi dinamiki: ekonomicheskie i politicheskie protsessy, ed. S. Yu. Malkov, L. E. Grinin, Moscow, Moskovskaya redaktsiya izdatel'stva "Uchitel"', 2016, pp. 7-26 (in Russ.). 